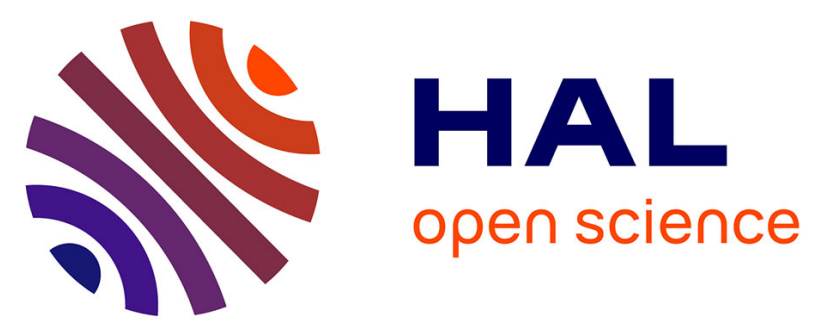

\title{
Multivariate analysis of the exposure and hazard of ceria nanomaterials in indoor aquatic mesocosms
}

\author{
Mohammad Nassar, Melanie Auffan, Catherine Santaella, Armand Masion, \\ Jérôme Rose
}

\section{- To cite this version:}

Mohammad Nassar, Melanie Auffan, Catherine Santaella, Armand Masion, Jérôme Rose. Multivariate analysis of the exposure and hazard of ceria nanomaterials in indoor aquatic mesocosms. Environmental science.Nano, 2020, 7 (6), pp.1661 - 1669. 10.1039/c9en01439j . hal-03065696

\section{HAL Id: hal-03065696 \\ https://hal-amu.archives-ouvertes.fr/hal-03065696}

Submitted on 15 Dec 2020

HAL is a multi-disciplinary open access archive for the deposit and dissemination of scientific research documents, whether they are published or not. The documents may come from teaching and research institutions in France or abroad, or from public or private research centers.
L'archive ouverte pluridisciplinaire HAL, est destinée au dépôt et à la diffusion de documents scientifiques de niveau recherche, publiés ou non, émanant des établissements d'enseignement et de recherche français ou étrangers, des laboratoires publics ou privés. 


\section{Multivariate Analysis of the Exposure and Hazard of Ceria Nanomaterials in Indoor Aquatic Mesocosms}

Nassar Mohammad ${ }^{a}$, Auffan Mélanie ${ }^{a, b^{*}}$, Santaella Catherine ${ }^{c}$, Masion Armand ${ }^{a}$, Rose Jérôme ${ }^{a, b}$

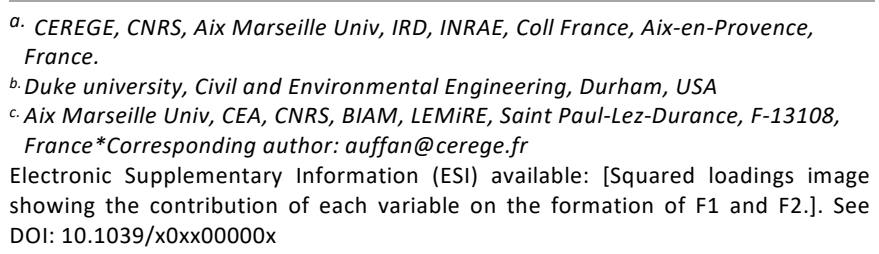

The vast diversity of applications uing nanomaterials and the enhanced physicochemical properties at the nanoscale have raised questions concerning their potential environmental risks. Assessing the risk of nanomaterials in a real ecosystem is extremely challenging because of the system complexity and the relevant environmental doses tested. To provide ultimate interpretations about nanomaterials risk assessment, we combined ceria nanomaterials behavior, fate and impact analysis within indoor aquatic mesocosms with multivariate analysis. PCA showed that the exposure scenario to $\mathrm{CeO}_{2}$ nanoparticles (NPs) constitutes the main parameter to consider while investigating the risk for a given ecosystem. Moreover, following a single pulse of $\mathrm{CeO}_{2} \mathrm{NPs}$, the global response of the pond ecosystem was time dependent. However, a multiple dosing contamination failed to significantly perturbate the system overtime. Finally, the NPs surface coating was found to play a secondary role and to affect the global response of the pond ecosystem on the short term only.

\section{INTRODUCTION}

The European Union (EU) regulation number 2018/1881 is a major milestone in addressing nanomaterials. Indeed, these materials graduated from a "recommendation" status, in the pioneering definition initiative in 2011, to a formal existence as an actual nano-sized compound in the REACH registration process, which as of Jan $1^{\text {st }}, 2020$, includes nano specific characterization requirements.

Since material registration becomes nano-specific, it is just a matter of time before current approaches differentiating between life cycle stages of traditional chemicals will be translated into their nanoscale compliant version. It is likely, similarly to traditional chemicals, that early life cycle stages of nanomaterials (i.e. occupational/production) are/will be better documented than the use- and end-of-life phases. However, from the point of view of the sustainability of nanotechnologies and environmental risk assessment, the focus should also be on these two last phases. Unfortunately, while progressing to the late life cycle stage, there are very few testing methods to evaluate environmental exposure and hazard, and these most often use model systems designed to determine a limited number of parameters. There is however an exception in the form of mesocosm testing ${ }^{1}$.

A mesocosm is an experimental system that reproduces a miniature ecosystem under controlled and conditions ${ }^{2} 34$. The strong appeal of this methodology is an unchallenged environmental relevance, provided contamination levels reflecting real or predicted situations. Working with such experimental devices is analytically challenging in terms of number of samples to be analyzed, measurements of bio-physico-chemical endpoints in complex matrices, etc. To counterbalance this, there is a definite need for alternative methods to make greater use of the potential of mesocosm experiments. To do so, such methods can/should take advantage of the fact that all parameters and biological endpoints are obtained under the same conditions. Indeed, it then becomes possible to examine possible correlations between parameters, thus providing information not available by examining each parameter separately. For example, the N4mics data visualization tool examining over 150 data sets, was used to show that the speciation of the entire nanocomposite had a larger influence on the toxicity to zebrafish than the nature of the components of the composite ${ }^{5}$. As a matter of fact, numerical and statistical approaches, and in particular Principal Component Analysis (PCA) are commonly used to treat large data sets, but they are still underutilized in the analysis of physicochemical parameters during mesocosm testing, although this methodology appears as a good candidate to benefit from multivariate analysis to counterbalance the bivariate analytical capabilities ${ }^{678}$.

In the present study, the relevance of multivariate analysis was tested with the dataset of freshwater mesocosms contaminated with $\mathrm{CeO}_{2}$ nanoparticles (NPs) ${ }^{2}{ }^{3}$. The goal was to determine the main variables that drive the behaviour and impact of NPs in aquatic mesocosms. These studies focused on $\mathrm{CeO}_{2}$ nanoparticles because of their global production estimated to be $\sim 10,000$ tons $^{9}$ with applications in electronics and optics, catalysts, energy and environment, coatings and paints 10111213141516 . However, their physicochemical properties such as a high specific surface area $\left(\approx 200 \mathrm{~m}^{2} / \mathrm{g}\right)$ and great reactivity 171819 have raised questions concerning their hazard and fate in the environment. Keller et al. $(2013)^{20}$ estimated that 8,200 tons per year of $\mathrm{CeO}_{2}$ might be released to landfills, 1,400 
tons per year to soils, 100 tons per year to air, and 300 tons per year to water. The exposure concentration selected by Tella et al. (2014 and 2015$)^{2}{ }^{3}$ between 0.1 and $1.3 \mathrm{mg} / \mathrm{L}$ of $\mathrm{CeO}_{2}$ are in the upper range of predicted environmental concentrations and in the lower range of already published studies 2122.

The dataset studied is made of physical-chemical and biological proxies measured in 16 mesocosms mimicking a pond ecosystem exposed to $\mathrm{CeO}_{2}$ NPs (citrate-coated or uncoated, $4 \mathrm{~nm}$ or $30 \mathrm{~nm}$ ). These NPs are representative of NPs used in wood protections ${ }^{23}$ and also as fuel additives ${ }^{15} 16$. The data were analyzed using PCA to identify and classify the predominant parameters governing the global response of the ecosystem mimicked in mesocosms viz. the time frame (short-, mid-terms), the type of NPs (coated, uncoated), the dosing scenarios (single versus multiple pulse), the initial concentration, etc.

\section{MATERIAL AND METHODS}

\section{Origin of the dataset}

Data used in this multivariate analysis come from experiments performed in freshwater indoor mesocosms contaminated with $\mathrm{CeO}_{2}$ NPs. Briefly, sixteen indoor mesocosms were set up to mimic a natural pond ecosystem. Natural sediments and organisms (picobenthos and the invertebrate Planorbarius corneus) were collected from a non-contaminated pond in the preserved Natura 2000 reserve network in southern France $(43.34361 \mathrm{~N}, 6.259663 \mathrm{E}$, altitude $107 \mathrm{~m}$ a.s.I.). Each mesocosm consisted of a layer of artificial sediments (adapted from ${ }^{24}$ ) made of $79 \%$ of $\mathrm{SiO}_{2}$ (SNL, France), $15 \%$ of kaolinite (Olterre, France), and $1 \%$ of $\mathrm{CaCO}_{3}$ (Sigma-Aldrich, US) covered with $300 \mathrm{~g}$ of water-saturated natural sediment containing primary producers (e.g., algae, bacteria). The tanks were filled with 46 $\mathrm{L}$ of Volvic ${ }^{\circledR}$ water with $\mathrm{pH}\left(\mathrm{pH}^{\sim 7.9}\right)$ and conductivity values (between 250 to $330 \mu \mathrm{S} / \mathrm{cm}$ ) close to those of the natural pond water. After a first phase of mesocosm equilibration and organism acclimation (viz. P. corneus), 12 mesocosms were contaminated with $\mathrm{CeO}_{2} \mathrm{NPs}$ and 4 were kept as control.

Two scenarios of $\mathrm{CeO}_{2}$ NPs contamination that can be encountered in real life were simulated during a month: (i) a single pulse (called 'mono' exposure scenario) of $69 \mathrm{mg}$ of NPs to achieve a total concentration of $1.3 \mathrm{mg} / \mathrm{L} \mathrm{of} \mathrm{CeO} 2$ NPs simulating NPs rain runoff or spills. and (ii) multiple dosing (called 'multi' exposure scenario) of 5.2 mg of NPs 3 times per week to reach a concentration of $1.1 \mathrm{mg} / \mathrm{L}$ after 28 days. The latter contamination scenario corresponds to a continuous point source discharge such as a wastewater treatment plant or industrial discharge.

Among the 16 mesocosms, 4 were kept as Controls and 12 were contaminated with the 3 types of commercially available $\mathrm{CeO}_{2}$ NPs. Citrate coated $\mathrm{CeO}_{2} \mathrm{NPs}\left(\sim 4 \mathrm{~nm}\right.$, Nanobyk ${ }^{\circledR}$, Byk additives and Instruments, Germany) were used to contaminate a total of 6 mesocosms ( 3 with the mono and 3 with the multi exposure scenario). Large bare $\mathrm{CeO}_{2}$ NPs ( $30 \mathrm{~nm}$, NanoGrain ${ }^{\circledR}$, Umicore, Germany) were used to contaminate 3 mesocosms using the mutli exposure scenario, and small bare $\mathrm{CeO}_{2} \mathrm{NPs}$ ( $\sim 4 \mathrm{~nm}$, Rhodia, France) to contaminate 3 mesocosms using the mono exposure

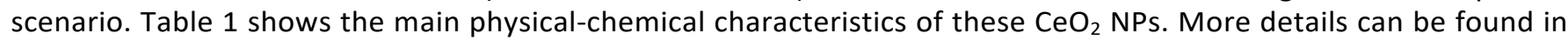
Tella et al. $(2014,2015)^{2} 3$.

\section{Implementation of the database}

Data were collected and gathered in a matrix containing 64 rows and 14 columns. While the rows list the 16 mesocosms implemented at each time point (4 time points), the columns detail the 14 variables studied to characterize the behavior, fate and impact of the NPs. Three types of variables were distinguished:

- Six quantitative environmental variables measured every 5 minutes in each mesocosm: $\mathrm{pH}$, oxidationreduction potential (ORP) in water column, ORP in the surficial sediment, conductivity (cond), dissolved $\mathrm{O}_{2}$ $\left(\mathrm{O}_{2}\right)$, Total Organic Carbon (TOC).

- Four quantitative response variables measured once per week in each mesocosm : cerium concentration in the water column ([Ce] tot water), cerium concentration in the surficial sediments ([Ce] tot sediment), a biomarker of total antioxidant capacity (TAOC), and a biomarker of oxidative stress level based on lipid oxidation products (TBARS, thiobarbituric acid-reactive substances) 2526 . TBARS and TAOC were measured on the digestive gland of $P$. corneus. For more details about these measurements see Tella et al. $(2014)^{3}$.

- Four qualitative variables: the exposure scenario (mono, multi, or control), the surface coating (none or citrate), the initial size of NPs $(\sim 4 \mathrm{~nm}$ and $\sim 30 \mathrm{~nm})$ and the sampling time point (time 7, time 14, time 21, time 28).

To get a symmetric dataset, quantitative environmental variables were averaged during $24 \mathrm{~h}$ at days $7,14,21$, and 28 .

\section{Statistical analysis}

Principal Components Regression (PCR) was used to detect patterns in the dataset and to describe linear relations between the quantitative and qualitative response variables. PCR is a regression method divided into three steps. First, a PCA is used to provide a data analysis that can explain the structure of correlations using linear combinations 
of the original data. Its use reduces and interprets data in a small space and presents them in a graphical form with the principle of double projection on the factorial axes 2728 . PCA can help distinguish fundamental differences in objects based on many variables ${ }^{29}$. Then, a linear regression is performed to predict a quantitative outcome variable (y) on the basis of one or multiple predictor variables $(x)$. Correlation and loading plots provided by PCR and PCA enable to study the relationship among quantitative variables, as well as between quantitative and qualitative variables. Data were centered and reduced using the correlation of Pearson.

Due to the long experimentation period, sampling incidents caused $\sim 3 \%$ of the data to be missing from the dataset. Herein, we predicted the missing data using linear regression based on Analysis of Covariance (ANCOVA) model. ANCOVA, which is a combination of Analysis of Variance (ANOVA) and linear regression, explains one quantitative variable via qualitative and quantitative variables.

In order to show clearly the clustering of data and observations the ellipses of confidence were used according to Fisher method with $95 \%$ as a percentage of certainty.

Table 1. Main physical-chemical characteristics of $\mathrm{CeO}_{2} \mathrm{NPs}$ used to contaminate the mesocosms. (* : in their stock suspensions)

\begin{tabular}{|c|c|c|c|c|c|c|}
\hline Name & $\begin{array}{l}\text { Surface } \\
\text { coating }\end{array}$ & $\begin{array}{l}\text { Particle } \\
\text { size } \\
\text { (TEM) }\end{array}$ & $\begin{array}{c}\text { Specific } \\
\text { surface } \\
\text { area }\left(\mathrm{m}^{2} / \mathrm{g}\right)\end{array}$ & $\begin{array}{c}\text { Average } \\
\text { Hydrodyna } \\
\text { mic } \\
\text { diameter * }\end{array}$ & $\begin{array}{l}\text { Isoelectric } \\
\text { point (IEP) }\end{array}$ & References \\
\hline $\begin{array}{c}\text { Bare } \mathrm{CeO}_{2} \\
\text { NPs }\end{array}$ & Uncoated & $\begin{array}{l}30 \\
\pm 18 \mathrm{~nm}\end{array}$ & $56 \pm 10$ & $90 \mathrm{~nm}$ & $\sim 7.8$ & 2 \\
\hline $\begin{array}{c}\text { Bare } \mathrm{CeO}_{2} \\
\text { NPs }\end{array}$ & Uncoated & $4 \pm 1.8 \mathrm{~nm}$ & $271 \pm 177$ & $8 \mathrm{~nm}$ & $\sim 7.5$ & 3 \\
\hline $\begin{array}{l}\text { Citrate- } \\
\text { coated } \\
\mathrm{CeO}_{2} \text { NPs }\end{array}$ & Citrate & $4 \pm 1.8 \mathrm{~nm}$ & $271 \pm 177$ & $8 \mathrm{~nm}$ & $>10$ & 23 \\
\hline
\end{tabular}

\section{RESULTS AND DISCUSSION}

Exposure scenario: the predominant parameter governing the global response of a freshwater ecosystem to $\mathrm{CeO}_{2} \mathrm{NPs}$

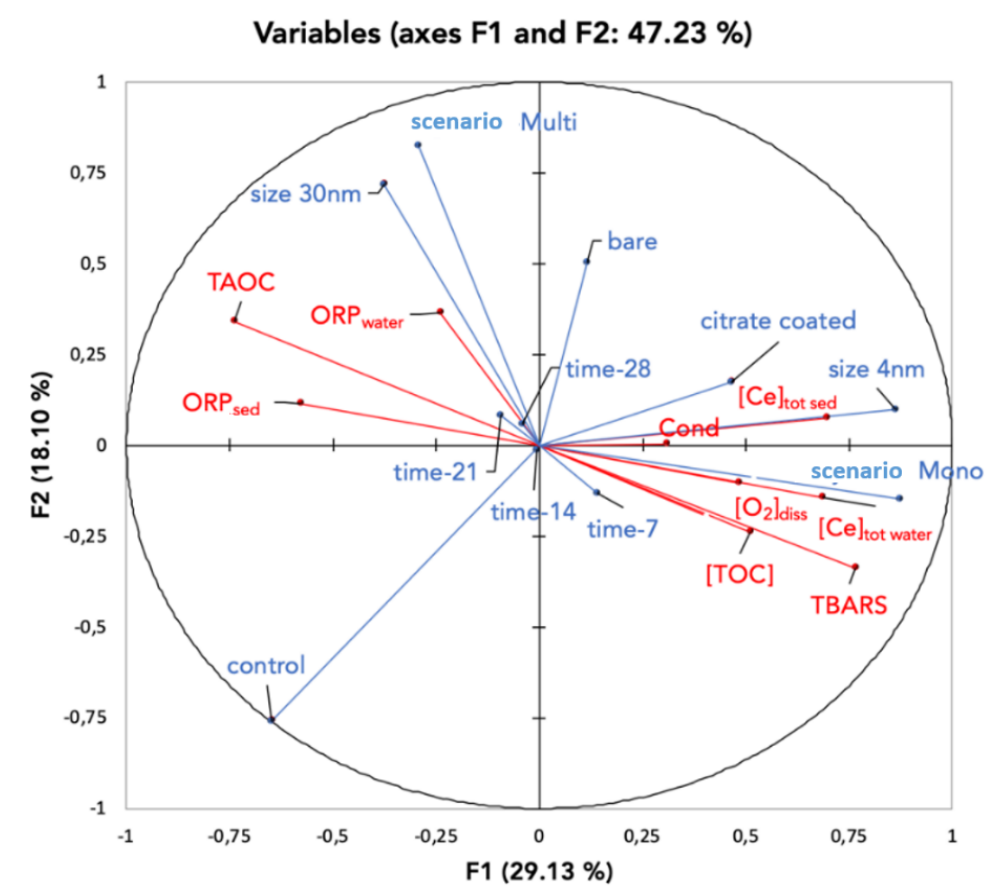

Figure 1: circle of correlation given by PCR and gathering 10 quantitative variables in red and 4 qualitative variables in blue. The two first principal axis F1 and F2 explained $29.13 \%$ and $18.10 \%$ of the variability, respectively. A small angle between two variables indicates a good correlation, no correlation at $90^{\circ}$, while if it tends to $180^{\circ}$ the variables are considered anti-correlated. The modulus of two arrows must be comparable and estimates the impact of each variable on the analysis. 
Correlation circle and loading plots provided by PCR and PCA respectively enable to study the relationship among quantitative variables, as well as between quantitative and qualitative response variables measured in the 16 indoor mesocosms. The first two components (F1 and F2) accounted for $47.23 \%$ of the variability.

The correlation plot (Figure 1) shows that four quantitative response variables ([Ce] tot water), [Ce] tot sediment, TAOC, and TBARS) and two qualitative modalities, exposure-Mono and size $4 \mathrm{~nm}$, contributed to the first component (F1). These variables characterize both the nature, the behaviour and impact of the $\mathrm{CeO}_{2} \mathrm{NPs}$ within the mimicked ecosystems. The second component arises mainly from three modalities of the qualitative variables: exposure scenario (multi and control), and NPs properties (bare surface and size $30 \mathrm{~nm}$ ).

To understand the relationships between all variables, the degree of linear correlations between them was calculated via Pearson correlation. In this paper, all correlation degree $(R>0.55)$ between quantitative variables were significant (p-value <0.05).

According to Figure 1 , TBARS was correlated to $[C e]$ tot water $(R=0.67)$, anti-correlated to TAOC $(R=-0.714)$, and a weak anti-correlation between TAOC and $[\mathrm{Ce}]$ tot water $(\mathrm{R}=-0.5)$ and $[\mathrm{Ce}]$ tot sediment $(\mathrm{R}=-0.35)$ was found.

Interestingly, PCR highlighted that the single pulse dosing (called mono exposure scenario) was correlated $(\mathrm{R} \sim 0.75$ ) to $[\mathrm{Ce}]_{\text {tot water }}$ and to biomarkers. However, no relevant correlation was detected neither with the multiple dosing (called multi exposure scenario) nor between the variables themselves within multi exposure scenario. The nature of the surface coating was not correlated $(R=0.2)$ to biomarkers and cerium concentrations in water column and surficial sediments during the 28 day-experiment when considered mono and multi exposure scenarios of $\mathrm{CeO}_{2} \mathrm{NPs}_{\text {within }}$ the same global analysis. However, when considering only the mono exposure scenario a correlation between the type of coating and $[\mathrm{Ce}]$ tot water $(R=0.89)$ and TBARS $(R=0.72)$ was observed at short-term exposure (dataset obtained at 7 days only). (See Figure S1)

The general trend highlighted that the exposure scenario constituted the main parameter to consider while investigating the risk for a given ecosystem exposed to $\mathrm{CeO}_{2} \mathrm{NPs}$. Squared loadings (Figure 2) highlight this conclusion and show that the exposure scenario contributes with 0.75 to the formation of F1. The relationships between the behaviour, fate, and impacts of $\mathrm{CeO}_{2} \mathrm{NPs}$ according to the scenario of contamination, as well as the importance of the NPs properties (surface coatings and size) on the short- and medium-term are discussed in more details in the following sections.

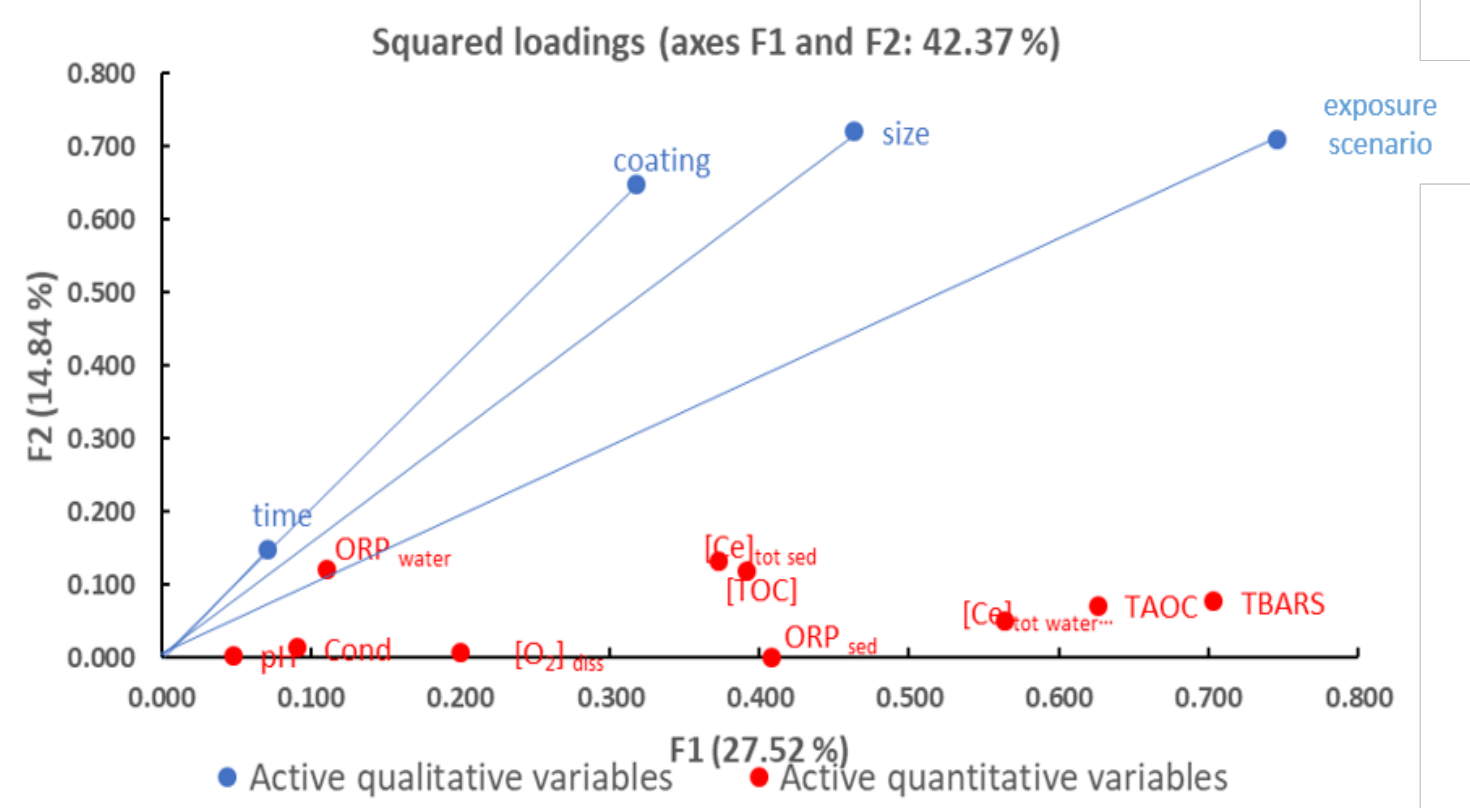

Figure 2: squared loadings plot showing the impact of each qualitative variables (in blue) and quantitative variables (in red) on the principal components F1 and F2.

Time-dependent global response of a pond ecosystem following a single pulse of $\mathrm{CeO}_{2} \mathrm{NPs}$

PCA was used to examine the significant interrelations among the variables as well as the clustering of the individuals (individual stands for the whole data set generated within one mesocosm at a given time point). The loading plots (F1, F2) obtained by PCA (Figure 3) gathered 64 observations corresponding to 16 mesocosms observed once per week for one month. In order to make the figure readable only mesocosms with high weights are shown in Figure 3. 


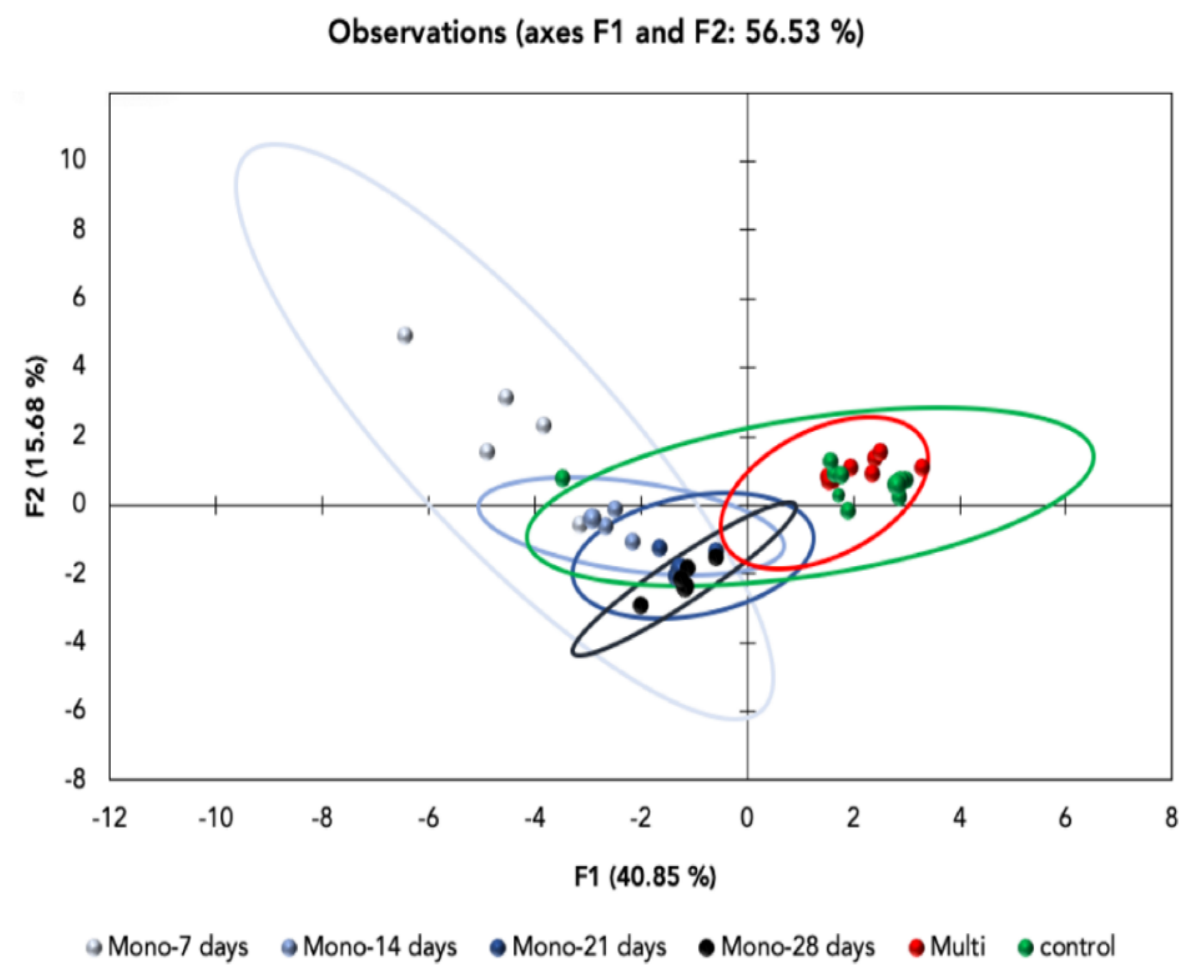

Figure 3: oading pots (F1, F2) gathering 64 observat ons custered according to the exposure scenario. Mesocosms in red correspond to the multi exposure scenario, contro mesocosms are shown in green and mono exposure scenario observat ons are dived into 4 groups: dav 7 , dav 14, day 21 and dav 28 . An e pse of conf dence enc rc es each group. To make the f gure readab e, mesocosms w $h$ low weights were dropped.

Figure 3 presents three groups clustered according to the contamination scenarios i.e. single pulse dosing, multiple dosing, and control group. Principal component F1 was mostly created by [Ce] tot water and TBARS through a contribution of 0.727 and 0.864 respectively, and F2 by the [Ce] tot water through a contribution of 0.552 (see Table S1). Over time, these three groups behave differently. No time-dependence was observed for the group corresponding to the multi exposure scenario(Figure 3, red) which overlapped with the control group (Figure 3, green).

Consequently, following a multiple dosing of low concentrations of $\mathrm{CeO}_{2} \mathrm{NPs}$, the ecosystem mimicked was not significantly destabilized overtime compared to controls. However, the group corresponding to the mono exposure scenario appeared to be time dependent. At early stage (day 7, Figure 3 light blue), the individuals of the mono exposure scenario were located far away from the center of the loading plots with a barycenter at $(-4.5 \pm 1,3.5 \pm 1)$. Then, the individuals of the mono exposure scenario gradually moved at day 14, 21 , and 28 to the center and close to the controls. To be noted that no significant difference is observed when considering the third dimension F3 (see Figure S2). Consequently, following a single pulse of $\mathrm{CeO}_{2} \mathrm{NPs}$ in aquatic mesocosms, the ecosystem was destabilized during the first few days, but gradually approached a state similar to control mesocosms.

Interestingly, the ellipse of confidence of the mono and multi exposure scenarios started to overlap after 14 days highlighting a convergence of the different systems after 2 weeks whatever the contamination scenarios. It is noteworthy that based only on the total $\mathrm{CeO}_{2}$ concentration injected in the mesocosms, such a convergence between the mono and multi exposure scenarios should have occurred at day 28 . Hence, the hypothesis that the global response of the ecosystem was driven by the total concentration of $\mathrm{CeO}_{2}$ in the system is not valid. However, among all the variables, the highest impact on the analysis was registered by [Ce] tot water and biomarkers (TBARS and TAOC) (Figure 2 and Figure S3).As the biomarkers are response variables, [Ce] tot water was considered the main variable that modulates the ecosystems behavior. In fact, it has been shown that [Ce] tot water remained quasi constant over time in the multi exposure scenario, whereas it drastically decreased in the mono exposure scenario ${ }^{4}$. The fast removal $(<7$ days) of Ce from the water column was attributed by Tella et al ${ }^{2}$. (2014) to both homo- and hetero-aggregation considering the surface properties of the $\mathrm{CeO}_{2} \mathrm{NPs}$ and the presence of natural colloids in the water column, as well as the slow solubility of $\mathrm{CeO}_{2} 30313233$. Colman et al. ${ }^{34}$ reached the similar conclusions regarding the behavior, fate, and impact of silver NPs in a year-long wetland mesocosm experiment. The initially higher silver concentrations in the water column in their single pulse dosing decreased due to colloidal destabilization within for 4 weeks to levels below those observed during their multiple dosing scenario. 


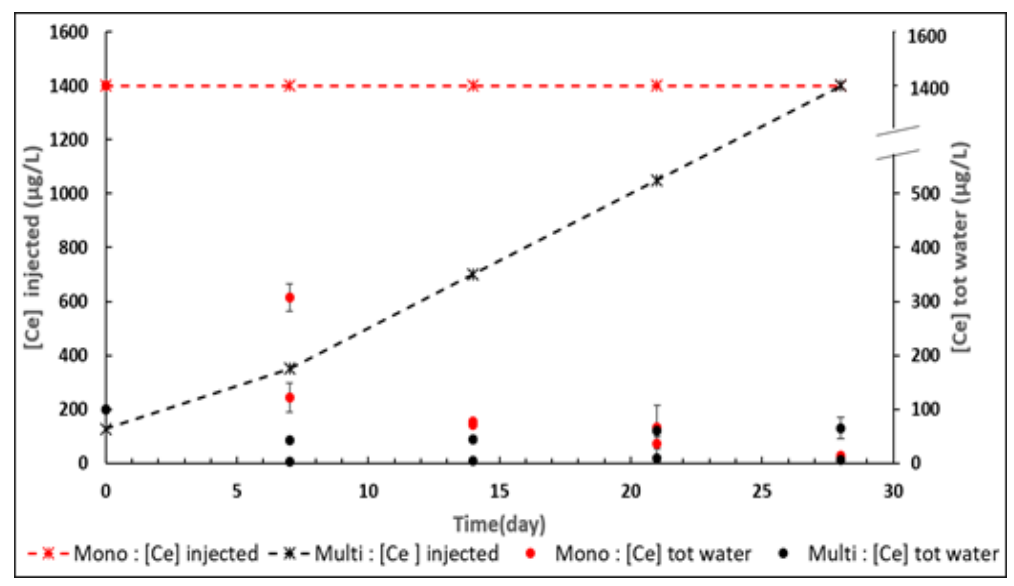

Figure 4: evolution over time of total Ce concentrat ons $n$ the water co umn (dotted line) versus tota Ce concentration njected in the mesocosms (full line) fo owng mu t $p$ e or mono dosing of NPs. Concentration in $\mu \mathrm{g} /$

Subsequently, both the global analysis and the experimental measurements of the fate (Figure 4) of NPs confirmed the hypothesis that the global response of the ecosystem is driven by the time frame of the bio-physical-chemical transformation of the NPs and their compartmentalization. Here, we show that depending on the scenario tested (e.g. mono exposure scenario for NPs rain runoff or spill, or multi exposure scenario for a continuous point source discharge such as a wastewater treatment plant or industrial discharge), a specific attention will have to be given to short-term versus medium-term responses.

\section{$\mathrm{CeO}_{2}$ NPs surface coating-dependent global response of the pond ecosystem on the short-term}

There have been several evidences in the literature for the impact of the surface coating of metal-based NPs on their toxicity ${ }^{23}$ as well as their behavior ${ }^{435}$ in aquatic environments. Here, we assess whether the surface coating of $\mathrm{CeO}_{2}$ affect the global response of the pond ecosystem on the short and mid-terms. The two scenarios of $\mathrm{CeO}_{2} \mathrm{NPs}$ contamination were taken separately because of their different time-sensitivity.

Figure 5 gathers and classifies 8 groups of individuals i.e. mesocosms exposed to the mono exposure scenario according to NPs surface coating and time. This loading plots (F1, F2) highlights that the individuals are distributed with respect to F1 which is, according to the squared loadings (see SI, Figure S4), mostly created by [Ce] tot water and TBARS through a contribution of $\sim 0.83$. The surface coating contributes to the formation of $F 2$ by 0.7 . While the ellipses of confidence of the bare $\mathrm{CeO}_{2} \mathrm{NPs}$ and coated $\mathrm{CeO}_{2} \mathrm{NPs}$ almost overlapped at days 14, 21 and 28, they were not clustered at a short time point (7 days). The clustering of bare and coated individuals according to F1 and F2 at 7 day highlights the short-term impact of surface coating on the exposure and hazard. Strikingly, this impact was also noticed by high correlations of surface coating to [Ce] tot water (0.89) and TBARS (0.75). At a medium-term, $(>14$ days) the system appears no longer sensitive to the surface properties of NPs. Similar findings were reported earlier ${ }^{3}$. A significant difference between bare and coated $\mathrm{CeO}_{2} \mathrm{NPs}$ treatments was observed at only one week after contamination with $19 \pm 16 \%$ and $41 \pm 15 \%$ of the Ce injected remaining in the water column respectively. After 7 days, the negatively-charged citrate coating ${ }^{36}$ was degraded (changes in chemical equilibrium, illumination) and both bare and aged coated NPs interacted similarly with natural colloids and settled ${ }^{37}{ }^{38}{ }^{30}$. Once in the surficial sediments, it is likely that the NPs strongly interact with the mineral surface, organic matter and the biofilm.

Figure 6 gathers and classifies 3 groups of individuals i.e. mesocosms exposed to the multi exposure scenario according to the NPs surface coating. This loading plots (F1, F3) highlights that the individuals are distributed mostly with respect to $\mathrm{F} 3$, an axes mostly created by [Ce] tot water through a contribution of 0.68 . Figure 6 shows that whatever the time point, the ellipses of confidences of control mesocosms and of mesocosms contaminated by bare NPs overlapped while mesocosms contaminated by coated $\mathrm{CeO}_{2} \mathrm{NPs}$ were clustered away from this group. This is likely due to the slower kinetics of the aging of the citrate coating compared to the rates of multi doses of fresh $\mathrm{CeO}_{2} \mathrm{NPs}$ into the mesocosms ${ }^{23}$. However, bare $\mathrm{CeO}_{2} \mathrm{NPs}$ having an isoelectric point close to $\mathrm{pH} 8$, their aggregation and settling is faster (a few minutes) than the rates of doses. Consequently, between two doses in the multi exposure scenario, coated $\mathrm{CeO}_{2} \mathrm{NPs}$ remained longer in the water column than bare $\mathrm{CeO}_{2} \mathrm{NPs}$. This result was corroborated through a correlation of 0.93 between citrate coated NPs injected using the multi exposure scenario and [Ce] tot water. It is noteworthy that despite the high correlation between the exposure variables (such as [Ce] tot water) and the surface coating, we did not find any correlation with hazard variables (such as TBARS) neither in short- nor in medium-term using the multi exposure contamination. 
There have been multiple suggestions in the literature on how to classify and prioritize NPs for safety assessment, including classification based on volume of production, chemistry, size, aspect ratio, surface properties, their adverse outcome pathways ${ }^{35}$. Based on the present experimental dataset and the performed global analysis, we observed that at the scale of $46 \mathrm{~L}$ mesocosms, the intrinsic properties of $\mathrm{CeO}_{2} \mathrm{NPs}$ cannot be used by themselves to classify and prioritize NPs for environmental risk assessment. A novel approach has to be used that interlinks physical-chemical descriptors of NPs, with the scenarios of exposure and the time scale.

Observations (axes F1 and F2: $56.44 \%$ )

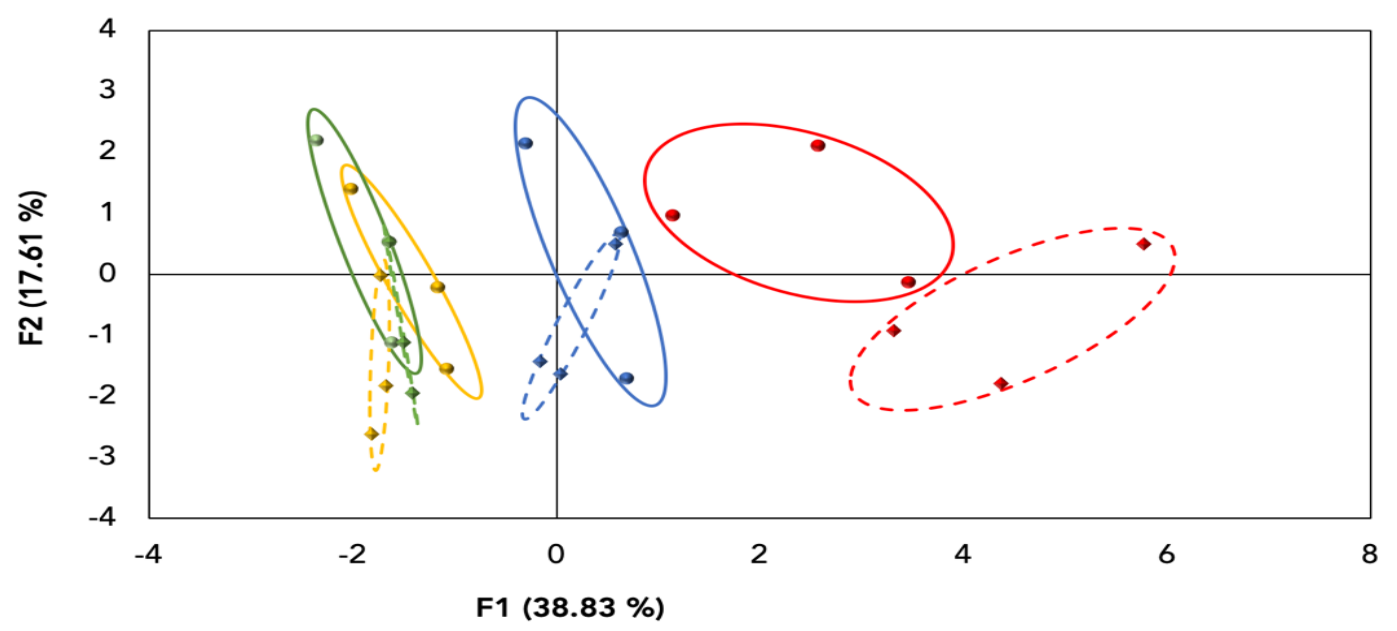

- bare day

- bare day 21

- bare day 14

- coated day 7 - -

$\rightarrow$ coated day 21

- bare day 28

- coated day 14 - - -

- coated day $28---$

Figure 5: loading plots (F1, F2) gathering 24 observations corresponding to the mesocosms contaminated by a single pulse of $\mathrm{CeO}_{2}$ NPs and clustered according to the surface coating. An ellipse of confidence encircles each group.

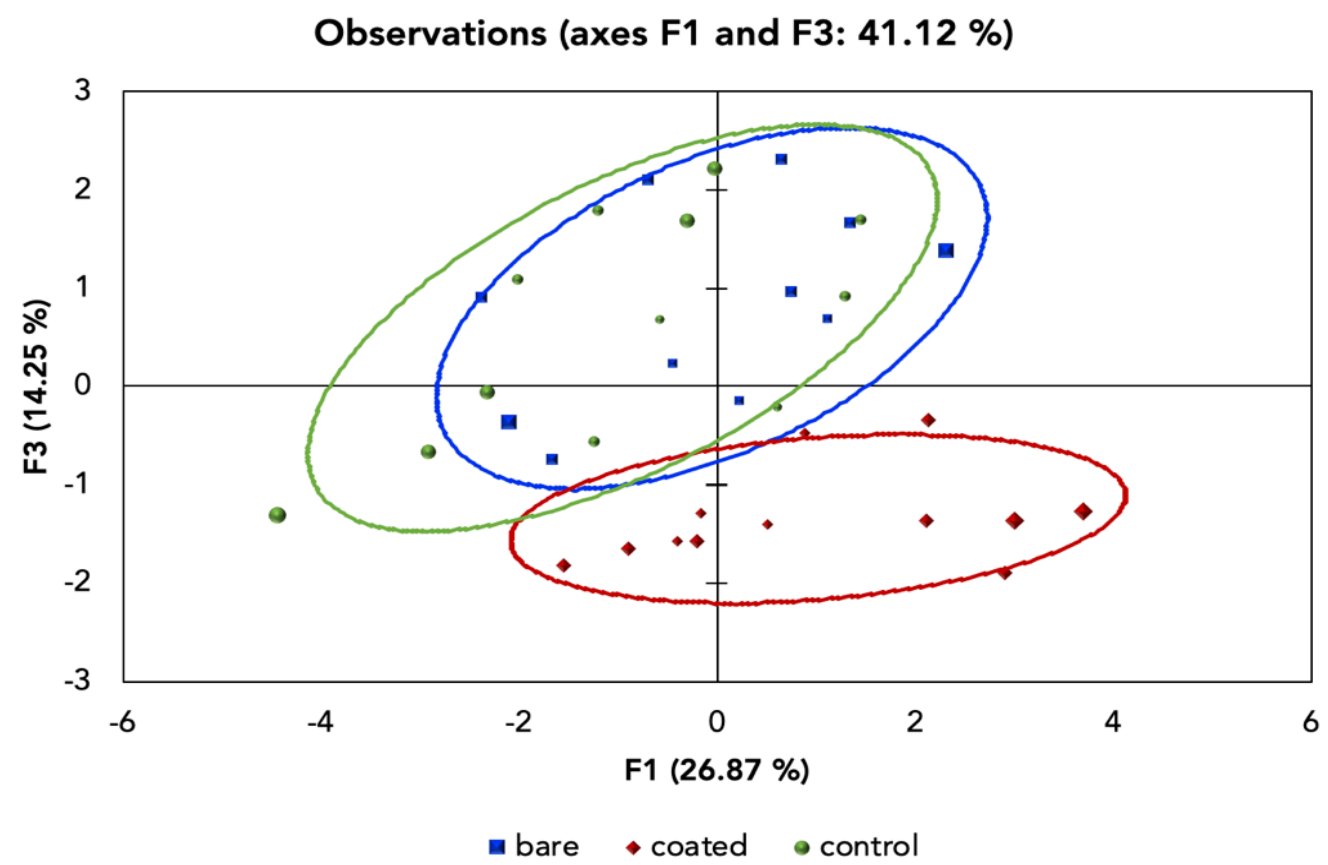

Figure 6: loading plots (F1, F3) gathering 36 observations corresponding to the mesocosms contaminated by multiple dosing scenario of $\mathrm{CeO}_{2} \mathrm{NPs}$ and grouped according to the surface coating. An ellipse of confidence encircles each group. 


\section{CONCLUSION}

Assessing the environmental risks related to nanotechnologies is technically and analytically challenging. Aquatic mesocosms have been shown to have the advantages of being adaptable and versatile exposure systems that allow different real-world exposure scenarios. For each scenario of exposure (duration, type of ecosystems, contamination scenario, NPs properties, etc.), the physical-chemical transformations of the NPs in the environment and their biological impacts are strongly correlated. Hence, all the attempts to consider only physical-chemical descriptors of NPs or only biological descriptors of targeted organisms to estimate their environmental risks appears too simplistic. Here, we showed that multivariate analysis could be an added value to mesocosm experiments in order to evaluate and predict the ecological consequences of NPs release into the environment. The performed global analysis showed that the scenario of contamination is the predominant stressor for a given ecosystem. Properties such as surface functionalization of the $\mathrm{CeO}_{2} \mathrm{NPs}$ (citrate coating, uncoated) lead to contrasted responses in aquatic mesocosms, only at the short-term following a punctual contamination scenario. At the medium-term, whatever the physical-chemical properties of $\mathrm{CeO}_{2}$ nanoparticles nor the contamination scenario tested, the global response (in term of exposure and hazard) obtained in our $46 \mathrm{~L}$ indoor aquatic mesocosms converged.

In this study PCA was not only an effective method to examine the interrelations among the variables but it also could be an added value in the development of environmental risk assessment of nanotechnology as well as in the safer by design NPs.

\section{CONFLICTS OF INTEREST}

There are no conflicts of interest to declare.

\section{ACKNOWLEDGMENTS}

This work has received funding from Excellence Initiative of Aix - Marseille University - A*MIDEX, a French "Investissements d'Avenir" program, through its associated Labex SERENADE project, as well as from the European project NanolnformaTIX, H2020-NMBP-TO-IND-2018-2020-814426. This work is also a contribution to the OSUInstitut Pythéas. The authors acknowledge the CNRS for the funding of the IRP iNOVE.

\section{REFERENCES}

1 M. Auffan, A. Masion, C. Mouneyrac, C. de Garidel-Thoron, C. O. Hendren, A. Thiery, C. Santaella, L. Giamberini, J.-Y. Bottero, M. R. Wiesner and J. Rose, Contribution of mesocosm testing to a single-step and exposure-driven environmental risk assessment of engineered nanomaterials, Nanolmpact, 2019, 13, 66-69.

2 M. Tella, M. Auffan, L. Brousset, E. Morel, O. Proux, C. Chanéac, B. Angeletti, C. Pailles, E. Artells, C. Santaella, J. Rose, A. Thiéry and J.-Y. Bottero, Chronic dosing of a simulated pond ecosystem in indoor aquatic mesocosms: fate and transport of CeO2 nanoparticles, Environ. Sci.: Nano, 2015, 2, 653-663.

3 M. Tella, M. Auffan, L. Brousset, J. Issartel, Kieffer, C. Pailles, E. Morel, C. Santaella, B. Angeletti, E. Artells, J. Rose, A. Thiéry and J.-Y. Bottero, Transfer, Transformation, and Impacts of Ceria Nanomaterials in Aquatic Mesocosms Simulating a Pond Ecosystem, Environ. Sci. Technol., 2014, 48, 9004-9013.

4 M. Auffan, M. Tella, C. Santaella, L. Brousset, C. Paillès, M. Barakat, B. Espinasse, E. Artells, J. Issartel, A. Masion, J. Rose, M. R. Wiesner, W. Achouak, A. Thiéry and J.-Y. Bottero, An adaptable mesocosm platform for performing integrated assessments of nanomaterial risk in complex environmental systems, Scientific Reports, 2014, 4, 5608.

5 S. C. Karcher, B. J. Harper, S. L. Harper, C. O. Hendren, M. R. Wiesner and G. V. Lowry, Visualization tool for correlating nanomaterial properties and biological responses in zebrafish, Environ. Sci.: Nano, 2016, 3, 1280-1292.

6 J. C. Joo, J. M. Lee, J.-R. Park, H. Ahn, J. H. Oh, S. Lee, H. M. Song and C. H. Ahn, Effects of Water Velocity and Specific Surface Area on Filamentous Periphyton Biomass in an Artificial Stream Mesocosm, Water, 2013, 5, 1723-1740.

7 K. P. Weber, M. Gehder and R. L. Legge, Assessment of changes in the microbial community of constructed wetland mesocosms in response to acid mine drainage exposure, Water Research, 2008, 42, 180-188.

8 M. C. Passarelli, I. Riba, A. Cesar, A. Newton and T. A. DelValls, Using a mesocosm approach to evaluate marine benthic assemblage alteration associated with CO 2 enrichment in coastal environments, Ecotoxicology and Environmental Safety, 2018, 157, 29-39. 
9 European Commission, Types and uses of nanomaterials, including safety aspects Accompanying the Communication from the Commission to the European Parliament, the Council and the European Economic and Social Committee on the Second Regulatory Review on Nanomaterials, Publications Office, Luxembourg, 2012.

10 S. Tsunekawa, T. Fukuda and A. J. Kasuya, Blue shift in ultraviolet absorption spectra of monodisperse CeO2-x nanoparticles, Journal of Applied Physics, 2000, 87, 1318-1321.

11 M. Hoshino, T. Mukai, T. Terasawa and I. Shinohara, Suprathermal electron acceleration in magnetic reconnection, Journal of Geophysical Research: Space Physics, 2001, 106, 25979-25997.

12 S.-H. Jung, T. Lee, K. Kim and S. L. George, Admissible two-stage designs for phase II cancer clinical trials, Stat Med, 2004, 23, 561-569.

13 S. M. Hirst, A. S. Karakoti, R. D. Tyler, N. Sriranganathan, S. Seal and C. M. Reilly, Anti-inflammatory properties of cerium oxide nanoparticles, Small, 2009, 5, 2848-2856.

14 S. Das, J. M. Dowding, K. E. Klump, J. F. McGinnis, W. Self and S. Seal, Cerium oxide nanoparticles: applications and prospects in nanomedicine, Nanomedicine (Lond), 2013, 8, 1483-1508.

15 B. Park, K. Donaldson, R. Duffin, L. Tran, F. Kelly, I. Mudway, J.-P. Morin, R. Guest, P. Jenkinson, Z. Samaras, M. Giannouli, H. Kouridis and P. Martin, Hazard and Risk Assessment of a Nanoparticulate Cerium Oxide-Based Diesel Fuel Additive-A Case Study, Inhalation Toxicology, 2008, 20, 547-566.

16 M. Auffan, M. Tella, W. Liu, A. Pariat, M. Cabié, D. Borschneck, B. Angeletti, G. Landrot, C. Mouneyrac, L. Giambérini and J. Rose, Structural and physical-chemical behavior of a $\mathrm{CeO} 2$ nanoparticle based diesel additive during combustion and environmental release, Environmental Science: Nano, 2017, 4, 1974-1980.

17 C. Fink, A. Hagemeyer, Z. Hogan and A. V. and J. Yoder, High Surface Area Cerium Oxide, http://www.eurekaselect.com/141967/article, (accessed 14 January 2019).

18 J. Yang, L. Lukashuk, H. Li, K. Föttinger, G. Rupprechter and U. Schubert, High Surface Area Ceria for CO Oxidation Prepared from Cerium t-Butoxide by Combined Sol-Gel and Solvothermal Processing, Catal Letters, 2014, 144, 403-412.

19 K. Reed, A. Cormack, A. Kulkarni, M. Mayton, D. Sayle, F. Klaessig and B. Stadler, Chemlnform Abstract: Exploring the Properties and Applications of Nanoceria: Is There Still Plenty of Room at the Bottom?, Environ. Sci.: Nano, , DOI:10.1039/C4EN00079J.

20 A. A. Keller, S. McFerran, A. Lazareva and S. Suh, Global life cycle releases of engineered nanomaterials, J Nanopart Res, 2013, 15, 1692.

21 L. F. Baker, R. S. King, J. M. Unrine, B. T. Castellon, G. V. Lowry and C. W. Matson, Press or pulse exposures determine the environmental fate of cerium nanoparticles in stream mesocosms, Environmental Toxicology and Chemistry, 2016, 35, 1213-1223.

22 A. Bour, F. Mouchet, S. Cadarsi, J. Silvestre, L. Verneuil, D. Baqué, E. Chauvet, J.-M. Bonzom, C. Pagnout, H. Clivot, I. Fourquaux, M. Tella, M. Auffan, L. Gauthier and E. Pinelli, Toxicity of $\mathrm{CeO} 2$ nanoparticles on a freshwater experimental trophic chain: A study in environmentally relevant conditions through the use of mesocosms, Nanotoxicology, 2015, 1-11.

23 M. Auffan, A. Masion, J. Labille, M.-A. Diot, W. Liu, L. Olivi, O. Proux, F. Ziarelli, P. Chaurand, C. Geantet, J.-Y. Bottero and J. Rose, Long-term aging of a CeO2 based nanocomposite used for wood protection, Environmental Pollution, 2014, 188, 17.

24 OECD. in Sediment-water Lumbricus toxicity test using spiked sediment (Organization for Economic Cooperation and Development, Paris, France, 2006).

25 D. Armstrong and R. Browne, in Free Radicals in Diagnostic Medicine: A Systems Approach to Laboratory Technology, Clinical Correlations, and Antioxidant Therapy, ed. D. Armstrong, Springer US, Boston, MA, 1994, pp. 43-58.

26 N. A. Botsoglou, D. J. Fletouris, G. E. Papageorgiou, V. N. Vassilopoulos, A. J. Mantis and A. G. Trakatellis, Rapid, Sensitive, and Specific Thiobarbituric Acid Method for Measuring Lipid Peroxidation in Animal Tissue, Food, and Feedstuff Samples, J. Agric. Food Chem., 1994, 42, 1931-1937.

27 J. de Lagarde, INITIATION A L'ANALYSE DES DONNEES. 3ème édition, Dunod, Paris, 3e edn., 1998.

28 M. Ringnér, What is principal component analysis?, Nature Biotechnology, 2008, 26, 303-304.

29 Numerical Ecology, Volume 24 - 2nd Edition, https://www.elsevier.com/books/numerical-ecology/legendre/978-0-44489249-2, (accessed 30 January 2019).

30 J. T. K. Quik, M. C. Stuart, M. Wouterse, W. Peijnenburg, A. J. Hendriks and D. van de Meent, Natural colloids are the dominant factor in the sedimentation of nanoparticles, Environ. Toxicol. Chem., 2012, 31, 1019-1022.

31 A. A. Keller, H. Wang, D. Zhou, H. S. Lenihan, G. Cherr, B. J. Cardinale, R. Miller and Z. Ji, Stability and Aggregation of Metal Oxide Nanoparticles in Natural Aqueous Matrices, Environmental Science \& Technology, 2010, 44, $1962-1967$.

32 R. Arvidsson, S. Molander, B. Sandén and M. Hassellöv, Challenges in Exposure Modeling of Nanoparticles in Aquatic Environments, Human and Ecological Risk Assessment (HERA), 2011, 17, 245-262.

33 A. R. Petosa, D. P. Jaisi, I. R. Quevedo, M. Elimelech and N. Tufenkji, Aggregation and Deposition of Engineered Nanomaterials in Aquatic Environments: Role of Physicochemical Interactions, Environ. Sci. Technol., 2010, 44, 65326549. 
34 B. P. Colman, L. F. Baker, R. S. King, C. W. Matson, J. M. Unrine, S. M. Marinakos, D. E. Gorka and E. S. Bernhardt, Dosing, Not the Dose: Comparing Chronic and Pulsed Silver Nanoparticle Exposures, Environ. Sci. Technol., 2018, 52, 1004810056.

35 C. Szakal, S. M. Roberts, P. Westerhoff, A. Bartholomaeus, N. Buck, I. Illuminato, R. Canady and M. Rogers, Measurement of Nanomaterials in Foods: Integrative Consideration of Challenges and Future Prospects, ACS Nano, $2014,8,3128-3135$.

36 R. M. Smith and A. E. Martell, Critical Stability Constants: Second Supplement, Springer US : Imprint : Springer, Boston, MA, 1989.

37 D. Zhou, A. I. Abdel-Fattah and A. A. Keller, Clay Particles Destabilize Engineered Nanoparticles in Aqueous Environments, Environ. Sci. Technol., 2012, 46, 7520-7526.

38 J. Zhao, F. Liu, Z. Wang, X. Cao and B. Xing, Heteroaggregation of Graphene Oxide with Minerals in Aqueous Phase, Environ. Sci. Technol., 2015, 49, 2849-2857.

39 I. Lynch, C. Weiss and E. Valsami-Jones, A strategy for grouping of nanomaterials based on key physico-chemical descriptors as a basis for safer-by-design NMs, Nano Today, 2014, 9, 266-270. 